\title{
ELM: A New, Simple, and Economic Assay to Measure Motility of Lymphatic Endothelial Cells
}

\author{
Fabio Torri, MD, Patrizia Dell'Era, $\mathrm{PhD}^{2}$, and Emirena Garrafa, $\mathrm{MD}^{1,3}$
}

\begin{abstract}
Background: Relatively few attempts have been made to set up an assay that allows the measurement of lymphatic endothelial cells (LECs) motility. Nowadays, the most widely used methods involve adaptation of the Boyden chamber method or the wound scratch assay, both of them showing some limitations due to long and expensive setup and high variability.

Methods and Results: We propose a new, economic, and easy to setup LEC Motility (ELM) assay that will contribute to the study of lymphangiogenesis. The experimental setup consists of extending the coating of the flask with extracellular matrix (ECM) proteins also at the area opposite to the cap, where the LECs will be initially seeded at various densities. The day after, the flasks will be inclined at an angle of about $20^{\circ}$ to cover the entire coated surface. Twenty-four hours later, flasks will be moved to the standard position, and the motility of the cells will be easily observed. Using the ELM assay, we were able to compare the motility rate of LECs isolated from different origins, or seeded on different substrates.

Conclusion: We propose the use of a new method to evaluate the motility of LECs: the ELM assay. This costeffective analysis has several advantages: It can be easily set up in any cell biology laboratory, can be carried out rapidly, and allows the monitoring of cellular motility for a long period.
\end{abstract}

Keywords: lymphatic endothelial cells, motility assay, economic, Boyden chamber, wound scratch assay

\section{Introduction}

$\mathbf{L}$ YMPHANGIOGENESIS, THE FORMATION of new lymphatic vessels from pre-existing ones, is an important biological process that is associated with different pathologies. ${ }^{1-4}$ It has long been overshadowed by research on angiogenesis because of the lack of markers to identify and distinguish lymphatic from blood endothelial cells together with the absence of a specific assay. Much progress has been made in recent years in identifying molecules specifically expressed on lymphatic vessels ${ }^{5-7}$ and in the setting up of in vitro and in vivo models of lymphangiogenesis, paving the way for a new area of research in the field. ${ }^{8-10}$ Obviously, no single model is able to elucidate the entire process of lymphangiogenesis associated with various pathological situations. To date, in vitro models of lymphangiogenesis have focused predominantly on migration, proliferation, and tubule formation by lymphatic endothelial cell (LEC) in response to exogenous inhibitory or stimula- tory agents. ${ }^{10-12}$ In particular, different assays have been proposed as a standard in vitro technique for probing collective LEC migration. ${ }^{9,10,13}$ Most of these methods are the result of an adaptation of assays already in use for studying angiogenesis, as in the modified Boyden chamber assay where LECs are plated on top of a coated filter, and migrate across it in response to a lymphangiogenic factor placed in the lower chamber. ${ }^{9,13}$ Although this assay is highly sensitive to small differences in concentration gradients, it intrinsically carries several drawbacks due to the technical difficulties of the setup, the troubles in maintaining transfilter gradients for long periods, and the inaccurate cell counts when small numbers of cells pass through the filter. On the other hand, in the adaptation of the wound-healing assay, ${ }^{8,10,14}$ a confluent monolayer is manually scratched with a pipette tip, needle, or other sharp tools ${ }^{14,15}$ to create a wound that induces the cells to migrate across the gap. In a typical experiment, the healing closure rate depends on the extension of the gap and on the

\footnotetext{
${ }^{1}$ Department of Surgery, ASST-Spedali Civili Brescia, Brescia, Italy.

${ }^{2}$ Cellular Fate Reprogramming Unit, Department of Molecular and Translational Medicine, University of Brescia, Brescia, Italy.

${ }^{3}$ Department of Molecular and Translational Medicine, University of Brescia, Brescia, Italy.
}

(c) Torri, Dell'Era, and Garrafa, 2017; Published by Mary Ann Liebert, Inc. This Open Access article is distributed under the terms of the Creative Commons Attribution Noncommercial License (http://creativecommons.org/licenses/by-nc/4.0/) which permits any noncommercial use, distribution, and reproduction in any medium, provided the original author(s) and the source are credited. 
molecules added to the cell culture medium. However, the mechanical scratch, which damages both cells and the underlying extracellular matrix (ECM), is manually created, thus limiting the generation of reproducible wounds. Then, injured cells must be quickly and completely removed, since the release of biological factors may interfere with the assay. Nevertheless, the unpredictable and uncontrollable damage to ECM can deeply affect cellular migration rates.

Recently, a new technical approach gave rise to an assay where fibroblasts or osteoblasts mobility has been measured. ${ }^{16}$ Considering the similarity of LECs with these type of cells in terms of developmental origin, we decided to modify this method, creating a new, economic, and easy to setup LEC Motility (ELM) assay that will surely contribute to the study of lymphangiogenesis.

\section{Materials and Methods}

\section{Characterization of LECs}

Fragments of normal lymph nodes and thymus were obtained from patients undergoing therapeutic surgical procedures, according to the principles listed in the Helsinki Declaration, and were immediately transferred on ice to the laboratory. Lymph node (Ln)- and Thymus (Th)-derived LECs were isolated from healthy tissues by double immunomagnetic purification as previously described. ${ }^{17,18}$ Cells were cultured in endothelial cell growth media (EGM) or endothelial cell basal media (EBM) (Lonza BioWhittaker, Walkersville, MD, USA) and grown in a humidified atmosphere at $37^{\circ} \mathrm{C}$ and $5 \% \mathrm{CO}_{2}$. The purity of Lnand Th-LECs was assessed by evaluating the expression of CD31 and LYVE-1 as previously described. ${ }^{4}$ Briefly, immunocytochemical studies were performed on cells seeded in Lab-Tek II chamber slides (Nalgene Nunc International, Rochester, NY, USA) that were coated with collagen type I.
Cells at confluence were fixed for 5 minutes with $4 \%$ paraformaldehyde in phosphate-buffered saline (PBS), $\mathrm{pH} 7.4$ for 10 minutes at room temperature. Cells were washed twice with PBS, incubated with $10 \%$ goat serum (Gibco, Grand Island, NY, USA) to block a specific binding, and finally incubated for 90 minutes at $37^{\circ} \mathrm{C}$ with either mouse monoclonal antibodies against CD31 (dilution 1:100; Dako, Carpinteria, CA, USA) or rabbit polyclonal antibodies against LYVE-1 (dilution 1:160; Reliatech, Braunschweig, Germany). To identify the presence of false positives due to nonspecific binding of the secondary antibody, samples from each type of LECs were treated in the same way, with buffer replacing the primary antibodies. After washing with PBS, cells were incubated for 45 minutes at room temperature with a 1:300 dilution of cyanine dye-labeled goat anti-mouse or goat anti-rabbit IgG (Jackson ImmunoResearch, West Grove, PA, USA). Air-dried cells were then mounted with Fluorosave (Calbiochem, La Jolla, CA, USA) and photographed by using a Zeiss Axiophot-2 microscope (Oberkochen, Germany).

\section{ELM assay}

Cell movement was measured on collagen type I- or fibronectin-coated (Sigma, St. Louis, MO, USA) T25 tissue culture flasks. At variance with standard techniques, the flasks were coated with ECM-derived proteins (collagens type I: $5 \mu \mathrm{g} / \mathrm{cm}^{2}$; fibronectin: $1 \mu \mathrm{g} / \mathrm{cm}^{2}$ ) also on the area opposite to the cap. Before use, flasks were rinsed with PBS, placed in the upright position and cells were added at different concentrations in the presence of EBM containing $2 \%$ fetal bovine serum (FBS). Cells were allowed to adhere to the end of the flask by overnight incubation at $37^{\circ} \mathrm{C}$. The day after, complete EGM was added to the flasks whereas EBM $2 \%$ FBS was used as negative control. All flasks were
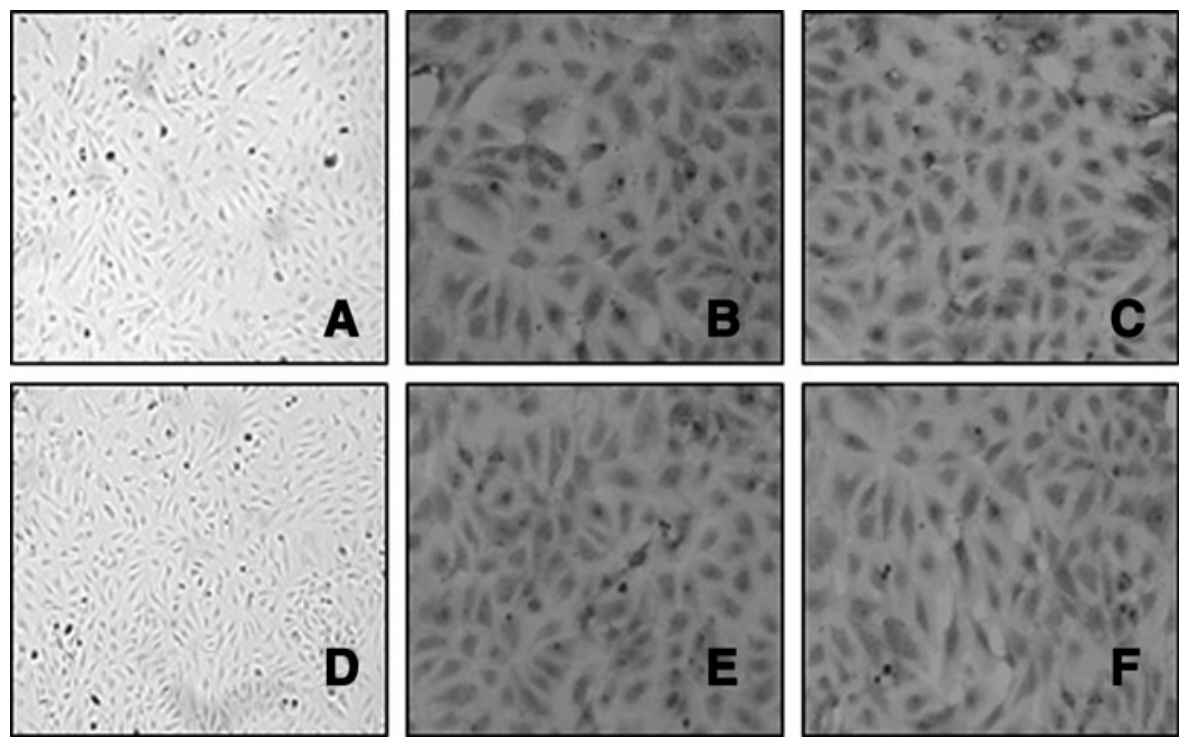

FIG. 1. Analysis of lymphatic cell lineage and purity of preparations. Confluent monolayers of Ln- and Th-LECs, seeded on collagen-coated culture slides, showed, at microscopic examination, an elongated shape typical of LECs with a prominent nucleus (A, D). Both Ln- and Th-LECs were positive for CD31 (B, E) and LYVE-1 (C, F). All data shown are representative of three independent experiments conducted in the same manner and with similar results. LECs, lymphatic endothelial cells; Ln, lymph node; Th, Thymus. 
subsequently inclined at an angle of about $20^{\circ}$ to cover with the medium the entire ECM-coated surface and to allow the cells to migrate from the bottom of the standing flask to the perpendicular ECM-coated observational surface. Twentyfour hours later, flasks were moved to the standard position, and the motility of the cells was easily observed for up to 10 days. Alternatively, after cell seeding, the 24 hour period of flask inclination can be avoided.

Cellular motility can be roughly observed by comparing the final position with the starting point. Indeed, LEC motility was then quantified by using a $10-\mu \mathrm{m}$ optical reticule grid eyepiece on an inverted microscope, which allowed the measurement in millimeters of the traveling distance of the cells. The referring starting point was represented by the edge of the two perpendicular coated surfaces. Cell motility rates can be analyzed daily, by measuring the distance from the edge of the flask to the leading edge of the cells. At the end of the assay, at least 20 measurements across the entire migration front were taken. Cells scattered across the monolayer or in the "empty" zone were ignored. Data were represented as the average migration distance for each condition ( \pm standard deviation). Statistical significance was determined by an analysis of variance $(p<0.05)$.

\section{Results}

\section{Characterization of LECS}

Isolated Ln- and Th-LECs were grown in a collagencoated flask and showed, at the microscopic examination, an elongated shape with a prominent nucleus, typical of LECs (Fig. 1A, D, respectively). The purity of cell preparations was ensured by the evidence that all cells, analyzed by immunocytochemistry staining, express CD31 (Fig. 1B, E) and the specific lymphatic marker LYVE-1 (Fig. 1C, F). Altogether,

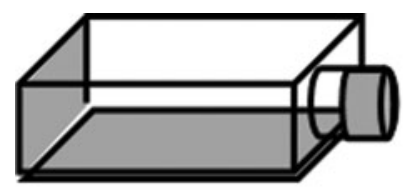

\section{A Coat T issue Culture Flasks} with Collagen type I

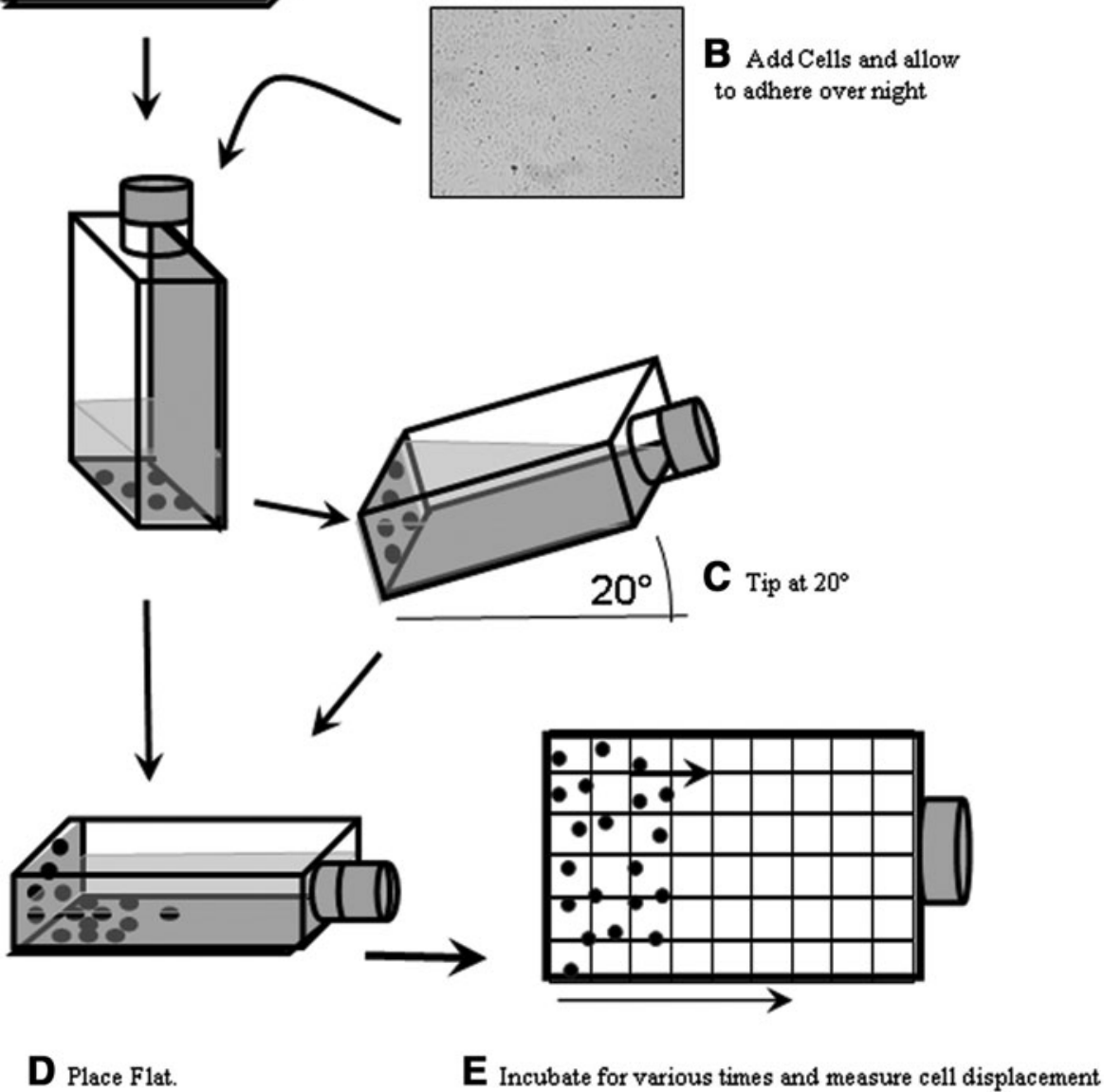

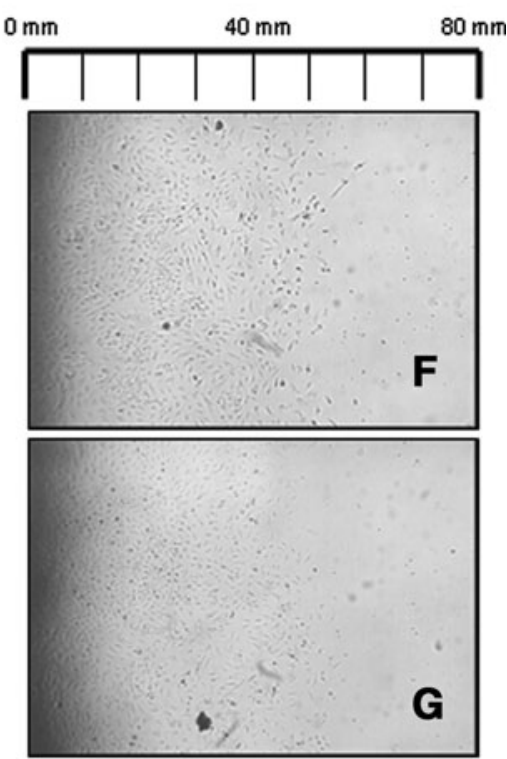

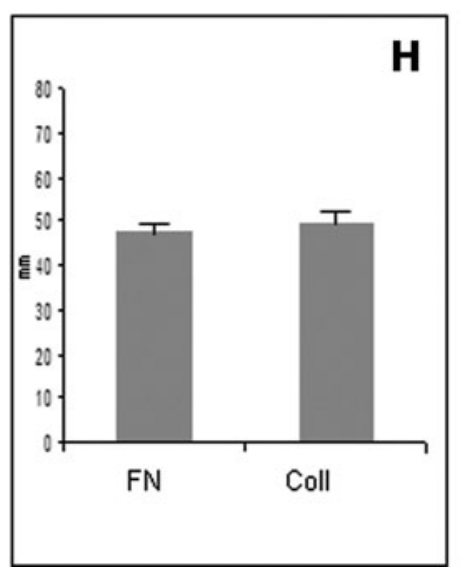

FIG. 2. Simplified cell motility ELM assay. T-25 tissue culture flasks were coated with either collagen type I or fibronectin in the gray areas, and LECs were added (A, B). After overnight incubation, flasks were inclined with an angle of $\sim 20^{\circ}$ (C) or in their normal position (D). Cells at the bottom of the flasks were allowed to migrate for up to 10 days. Cell motility rates could be analyzed daily, by measuring the distance from the edge of the flask to the leading edge of the cells (E) (Modified by Lallier et al. ${ }^{16}$ ). Quantification of cells in fibronectin (F) or collagen type I (G)-coated flasks where no significant differences $(p>0.05)$ were observed $(\mathbf{H})$. All data shown are representative of three independent experiments conducted in the same manner and with similar results. ELM, Easy to Setup LEC Motility. 


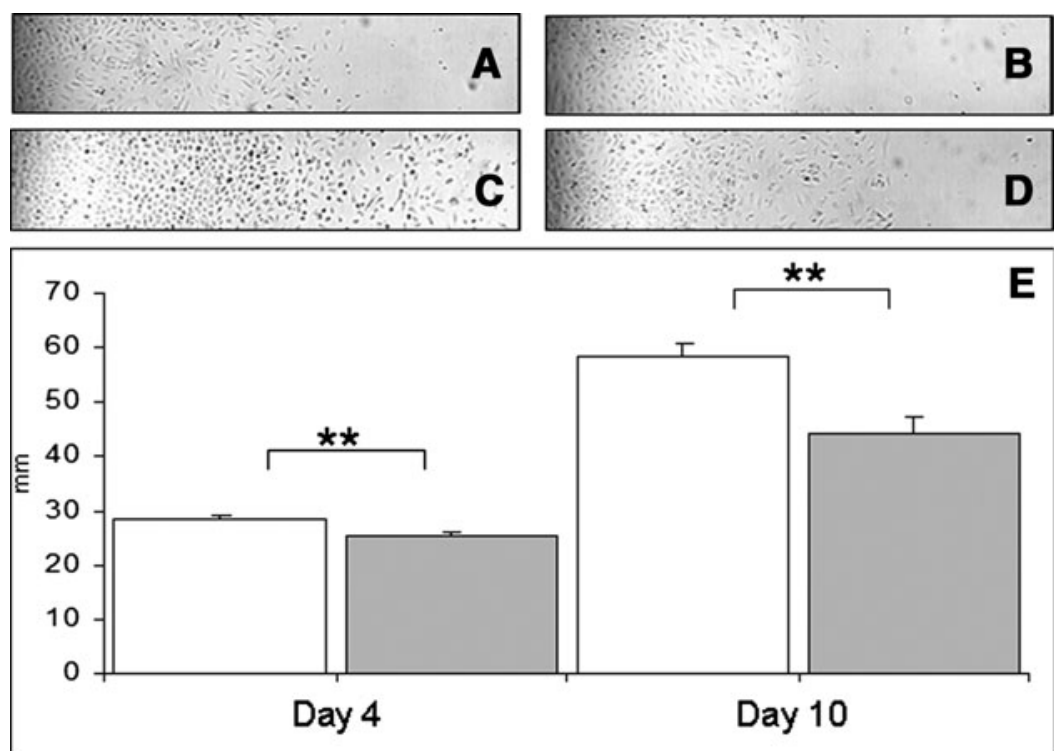

FIG. 3. ELM quantification. Ln-LEC (white bars) and Th-LEC (gray bars) motility was observed at day 1 (A and B, respectively), day $4(\mathbf{C}, \mathbf{D})$, and day $10(\mathbf{E}, \mathbf{F})$. The graph at the bottom of the figure represents the quantification of the ELM assay $(* * p<0.05)$. All data shown are representative of three independent experiments conducted in the same manner and with similar results.

these results provide evidence of the initial lymphatic lineage of cultured cells.

\section{ELM assay}

To evaluate cellular motility, the ELM assay was set up by using Ln-LECs grown on either collagen type I or fibronectin coating (Fig. 2A). We initially tested some dilutions of the LECs: 1,2 , or $5 \times 10^{5}$ cells/mL in EBM $2 \%$ FBS; cells were left to adhere for 24 hours at the bottom of the flasks as illustrated in Figure 2B. The smaller concentration, $10^{5}$ cells $/ \mathrm{mL}$, did not form a straight and tightened cellular front whereas the higher concentration, $5 \times 10^{5}$ cells $/ \mathrm{mL}$, resulted in floating cells that would interfere with the assay by releasing substances influencing motility or by subsequent adhesion in the empty area, far from the starting point. Then, the concentration of $2 \times 10^{5}$ cells $/ \mathrm{mL}$ gave the best results on both collagen I- and fibronectin-coated flasks, because of the homogeneous cellular front and very few cells floating in the supernatant. After cell attachment, the flasks were inclined at an angle of $\sim 20^{\circ}$ for an additional 24 hours. This passage, which could be omitted in specific cases, allows the cells to move from the bottom of the flask to the standard visible surface, and to form the homogeneous cellular front that is required for ELM evaluation. As shown in Figure 2, the coating of either collagen I or fibronectin did not significantly change the cellular migration rate that was comparable between the two conditions with no significant differences $(p>0.05)$. Indeed, tilting the flasks to an angle of $20^{\circ}$ reduced the number of randomly scattered cells. Cellular motility was monitored daily and finally analyzed and scored as described in materials and methods. The movement of LECs maintained in EGM was evident when compared with either cells seeded in untreated tissue culture flasks, where cells probably did not adhere, or cells grown in EBM that represented our negative control (data not shown). The impossibility of mi- croscopically controlling the initial cell seeding at the bottom of the standing flask should be noted.

We used the ELM assay to compare the motility of LECs derived from either lymph node or thymus. Cells were seeded on collagen type I at the identified concentration, and the different samples were observed daily and photographed (Fig. 3). As shown, Ln-LECs have a significantly higher motility rate when compared with Th-LECs. Since the cellular motility can be influenced by adhesion molecules, which regulate the interactions between cells and ECM, the surface expression of intracellular adhesion molecule 1 (ICAM-1) and vascular adhesion molecule 1 (VCAM-1) was assayed in Ln- and Th-LECs subjected to ELM assay. At day 4 , cells were trypsinized and decorated with fluorescein isothiocyanate-conjugated specific monoclonal antibodies. Flow cytometry data showed that Ln-LECs constitutively express higher levels of ICAM-1 in both EGM and EBM medium when compared with Th-LECs.

\section{Discussion}

Different research articles have been published in the past 30 years that describe the role of lymphangiogenesis in the onset and/or progression of different diseases., ${ }^{2,22}$ One of the problems faced by lymphangiogenesis researchers is the difficulty of finding suitable methods for assessing the effects of regulators of the response. The ideal assay would be reliable, technically straightforward, easily quantifiable, and economic. We propose a new, ELM assay that will surely contribute to the study of lymphangiogenesis. We believe that the big improvement of the ELM assay resides in the fact that cell motility can be analyzed for a period of up to 10 days, during which migration is not much influenced by proliferation, since those cells have a doubling time of different days. ${ }^{17}$

In our experiments, we used LECs isolated from fresh lymph nodes and thymus that were characterized by the 


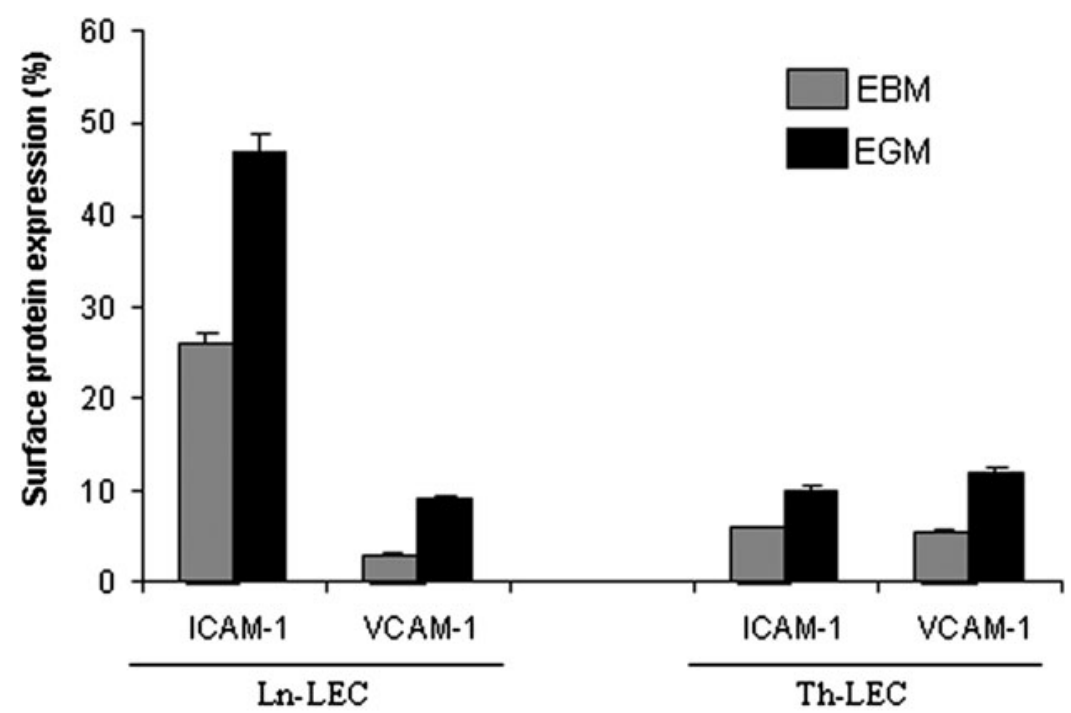

FIG. 4. Surface expression of adhesion molecules. The level of surface expression of ICAM-1 and VCAM-1 was assayed by flow cytometry on Ln- and Th-LECs subjected to ELM assay and grown in EBM or EGM. All data shown are representative of three independent experiments conducted in the same manner and with similar results. EBM, endothelial cell basal media; EGM, endothelial cell growth media; ICAM-1, intracellular adhesion molecule 1; VCAM-1, vascular cell adhesion molecule 1.

expression of CD31 and the specific lymphatic marker LYVE-1. Once characterized, we used Ln-LECs to identify the number of cells to be seeded in a $25 \mathrm{~cm}^{2}$ flask; the concentration of $2 \times 10^{5}$ cells gives a homogeneous starting point and reduces the number of cells randomly floating in the supernatant that could, eventually, adhere randomly to the flask. As expected, no motility was observed when flasks without coating were used, but this is probably related to the fact that, in our experience, LECs are not able to adhere to the uncoated flask. Incubation of both tilted flask lying flat and directly lying flat results in comparable cellular adhesion, even if the number of scattered cells was higher when the tilted flask passage was avoided. Since cell death could influence quantification, isolated LECs should be used at early passages when mortality is almost absent. No differences were observed on motility when cells were seeded on either fibronectin or collagen type I, even if we routinely use a collagen-coated flask to grow and expand LECs in our laboratory.

A different motility rate was observed when comparing Lnand Th-LECs. These data are in accordance with recent studies demonstrating that LECs derived from different organ possess distinct characteristics, including cell surface markers, growth characteristics, and chemokine or cytokine production, ${ }^{23-26}$ which could, indeed, influence motility. Cellular adhesion molecules are cell membrane receptors that mediate several interactions that are known to play a role in a variety of physiological and pathological conditions related to cellmatrix contact. The difference in motility could, indeed, derive from the altered expression of ICAM-1 on Ln- versus Th-LECs as shown in Figure 4, where, even in the resting status simulated by cultivation in EBM, cellular adhesion molecules were strongly overexpressed by Ln-LECs. Of course, many other factors would surely be involved in the different motility of the two type of LECs, but this was not the goal of our study. Even if the ELM assay is not useful to monitor short time-induced motility, we believe that it has different advantages compared with what is already de- scribed in the literature (Table 1). Currently, in vivo assays are time-consuming, costly, prone to high variability, and difficult to quantify. The assay we described is easy to set in any laboratory, since it requires basic tools, can be carried out rapidly, and is clearly quantified. Limitation such as the

Table 1. IN Vitro LyMPHANGIOGENESIS AsSAY: STRENGTHS AND WEAKNESSES

\begin{tabular}{|c|c|c|}
\hline & Advantages & Disadvantages \\
\hline $\begin{array}{l}\text { Boyden } \\
\text { chambers }\end{array}$ & $\begin{array}{l}\text { - Measure migration } \\
\text { in response to a } \\
\text { gradient } \\
\text { - Extremely sensitive } \\
\text { to small changes in } \\
\text { concentration }\end{array}$ & $\begin{array}{l}\text { - Technical difficulty } \\
\text { - Problems in } \\
\text { maintaining trans } \\
\text { filter gradients for } \\
\text { prolonged periods } \\
\text { - Difficulty in } \\
\text { obtaining accurate } \\
\text { cell counts when } \\
\text { small numbers of } \\
\text { cells traverse the } \\
\text { filter }\end{array}$ \\
\hline $\begin{array}{l}\text { Wound } \\
\text { assay }\end{array}$ & $\begin{array}{l}\text { - Easy to set up } \\
\text { - Economic }\end{array}$ & $\begin{array}{l}\text { - Difficult to generate } \\
\text { reproducible } \\
\text { wounds } \\
\text { - Release factors } \\
\text { from the damaged } \\
\text { cells } \\
\text { - Damage the ECM } \\
\text { - Impossible to } \\
\text { monitor long } \\
\text { periods }\end{array}$ \\
\hline $\begin{array}{l}\text { ELM } \\
\text { assay }\end{array}$ & $\begin{array}{l}\text { - Easy to set up } \\
\text { - Reproducible } \\
\text { - Release of factors } \\
\text { from damaged cells } \\
\text { is avoided } \\
\text { - No damage of ECM } \\
\text { - Economic }\end{array}$ & $\begin{array}{l}\text { - Not very useful for } \\
\text { monitoring short } \\
\text { period effect }\end{array}$ \\
\hline
\end{tabular}

ECM, extracellular matrix; ELM, Easy to Setup LEC Motility. 
release of factors from damaged cells is avoided, no damage of ECM is induced, and it is possible to monitor cellular motility for several days. All the advantages listed earlier, together with the economic costs of the method, support the utility of the ELM assay for studying motility of LECs.

\section{Author Disclosure Statement}

No competing financial interests exist.

\section{References}

1. Podgrabinska S, Skobe M. Role of lymphatic vasculature in regional and distant metastases. Microvasc Res 2014; 95: 46-52.

2. Liao S, Padera TP. Lymphatic function and immune regulation in health and disease. Lymphat Res Biol 2013; 3: 136-143.

3. Spinella F, Garrafa E, Di Castro V, Rosanò L, Nicotra MR, Caruso A, Natali PG, Bagnato A. Endothelin-1 stimulates lymphatic endothelial cells and lymphatic vessels to grow and invade. Cancer Res 2009; 6:2669-2676.

4. Garrafa E, De Francesco M, Solaini L, Giulini SM, Bonfanti C, Ministrini S, Caimi L, Tiberio GA. Lymphatic endothelial cells derived from metastatic and non-metastatic lymph nodes of human colorectal cancer reveal phenotypic differences in culture. Lymphology 2015; 6:6-14.

5. Petrova TV, Makinen T, Makela TP, Saarela J, Virtanen I, Ferrell RE, Finegold. DN, Kerjaschki D, Yla-Herttuala S, Alitalo K. Lymphatic endothelial reprogramming of vascular endothelial cells by the Prox-1 homeoboxtranscription factor. EMBO J 2002; 21:4593-4599.

6. Banerji S, Ni J, Wang SX, Clasper S, Su J, Tammi R, Jones M, Jackson DG. LYVE-1, a new homologue of the CD44 glycoprotein, is a lymph-specific receptor for hyaluronan. J Cell Biol 1999; 144:789-801.

7. Kahn HJ, Marks A. A new monoclonal antibody, D2-40, for detection of lymphatic invasion in primary tumors. Lab Invest 2002; 9:1255-1257.

8. Kazenwadel J, Secker GA, Betterman KL, Harvey NL. In vitro assays using primary embryonic mouse lymphatic endothelial cells uncover key roles for FGFR1 signaling in lymphangiogenesis. PLoS One 2012; 7:2979-2994.

9. Tutunea-Fatan E, Majumder M, Xin X, Lala PK. The role of CCL21/CCR7 chemokine axis in breast cancer-induced lymphangiogenesis. Mol Cancer 2015; 10:14-35.

10. Bruyère $\mathrm{F}$, Noël $\mathrm{A}$. Lymphangiogenesis: In vitro and in vivo models. FASEB J 2010; 24:8-21.

11. Yang Y, Gao Z, Ma Y, Teng H, Liu Z, Wei H, Lu Y, Cheng X, Hou L, Zou X. Fucoidan inhibits lymphangiogenesis by downregulating the expression of VEGFR 3 and PROX1 in human lymphatic endothelial cells. Oncotarget 2016; 7: 38025-38035.

12. Spinella F, Caprara V, Garrafa E, Di Castro V, Rosanò L, Natali PG, Bagnato A. Endothelin axis induces metalloproteinase activation and invasiveness in human lymphatic endothelial cells. Can J Physiol Pharmacol 2010; 8:782787.

13. Schanz A, Lukosz M, Hess AP, Baston-Büst DM, Krüssel JS, Heiss C. hCG stimulates angiogenic signals in lymphatic endothelial and circulating angiogenic cells. J Reprod Immunol 2015; 110:102-108.

14. Jonkman JE, Cathcart JA, Xu F, Bartolini ME, Amon JE, Stevens KM, Colarusso P. An introduction to the wound healing assay using live-cell microscopy. Cell Adh Migr 2014; 8:440-451.

15. Staton CA, Stribbling SM, Tazzyman S, Hughes R, Brown NJ, Lewis CE. Current methods for assaying angiogenesis in vitro and in vivo. Int J Exp Pathol 2004; 5:233-248.

16. Lallier TE, Miner QW Jr, Sonnier J, Spencer A. A simple cell motility assay demonstrates differential motility of human periodontal ligament fibroblasts, gingival fibroblasts, and pre-osteoblasts. Cell Tissue Res 2007; 328:339354.

17. Garrafa E, Trainini L, Benetti A, Saba E, Fezzardi L, Lorusso B, Borghetti P, Bottio T, Ceri E, Portolani N, Bonardelli S, Giulini SM, Annibale G, Corradi A, Imberti L, Caruso A. Isolation, purification, and heterogeneity of human lymphatic endothelial cells from different tissues. Lymphology 2005; 4:159-166.

18. Garrafa E, Alessandri G, Benetti A, Turetta D, Corradi A, Cantoni AM, Cervi E, Bonardelli S, Parati E, Giulini SM, Ensoli B, Caruso A. Isolation and characterization of lymphatic microvascular endothelial cells from human tonsils. J Cell Physiol 2006; 1:107-113.

19. Jurisic G, Detmar M. Lymphatic endothelium in health and disease. Cell Tissue Res 2009; 1:97-108.

20. Garrafa E, Caprara V, Di Castro V, Rosanò L, Bagnato A, Spinella F. Endothelin-1 cooperates with hypoxia to induce vascular-like structures through vascular endothelial growth factor-C, -D, and -A in lymphatic endothelial cells. Life Sci 2012; 91:638-643.

21. Spinella F, Caprara V, Cianfrocca R, Rosanò L, Di Castro V, Garrafa E, Natali PG, Bagnato A. The interplay between hypoxia, endothelial and melanoma cells regulates vascularization and cell motility through endothelin-1 and vascular endothelial growth factor. Carcinogenesis 2014; 4: 840-848.

22. Padera TP, Meijer EF, Munn LL. The lymphatic system in disease processes and cancer progression. Annu Rev Biomed Eng 2016; 11:125-158.

23. Garrafa E, Imberti L, Tiberio G, Prandini A, Giulini SM, Caimi L. Heterogeneous expression of toll-like receptors in lymphatic endothelial cells derived from different tissues. Immunol Cell Biol 2001; 3:475-481.

24. Kriehuber E, Breiteneder-Geleff S, Groeger M, Soleiman A, Schoppmann SF, Stingl G, Kerjaschki D, Maurer D. Isolation and characterization of dermal lymphatic and blood endothelial cells reveal stable and functionally specialized cell lineages. J Exp Med 2001; 194:797-808.

25. Podgrabinska S, Braun P, Velasco P, Kloos B, Pepper MS, Skobe M. Molecular characterization of lymphatic endothelial cells. Proc Natl Acad Sci U S A 2002; 25:1606916074.

26. Kawai Y, Hosaka K, Kaidoh M, Minami T, Kodama T, Ohhashi T. Heterogeneity in immunohistochemical, genomic, and biological properties of human lymphatic endothelial cells between initial and collecting lymph vessels. Lymphat Res Biol 2008;6:15-27.

Address correspondence to: Emirena Garrafa

Department of Molecular and Translational Medicine Viale Europa 11

University of Brescia Brescia 25100

Italy

E-mail: emirena.garrafa@unibs.it 